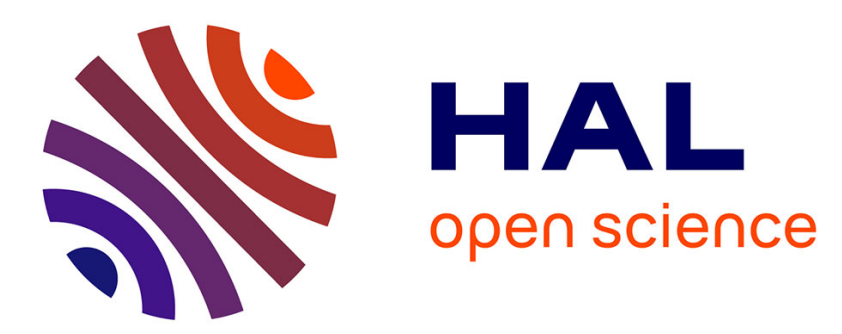

\title{
Conditions for optimum photothermal discrimination of subsurface thermal inhomogeneities
}

\author{
U. Seidel, A. Glazov, Karsten Haupt, H. Walther, J. Burt, B. Bein, J. Pelzl
}

\section{To cite this version:}

U. Seidel, A. Glazov, Karsten Haupt, H. Walther, J. Burt, et al.. Conditions for optimum photothermal discrimination of subsurface thermal inhomogeneities. Journal de Physique IV Proceedings, 1994, 04 (C7), pp.C7-555-C7-558. 10.1051/jp4:19947130 . jpa-00253185

\section{HAL Id: jpa-00253185 https://hal.science/jpa-00253185}

Submitted on 1 Jan 1994

HAL is a multi-disciplinary open access archive for the deposit and dissemination of scientific research documents, whether they are published or not. The documents may come from teaching and research institutions in France or abroad, or from public or private research centers.
L'archive ouverte pluridisciplinaire HAL, est destinée au dépôt et à la diffusion de documents scientifiques de niveau recherche, publiés ou non, émanant des établissements d'enseignement et de recherche français ou étrangers, des laboratoires publics ou privés. 
JOURNAL DE PHYSIQUE IV

Colloque C7, supplément au Journal de Physique III, Volume 4, juillet 1994

\title{
Conditions for optimum photothermal discrimination of subsurface thermal inhomogeneities
}

\author{
U. Seidel, A. Glazov, K. Haupt, H.G. Walther, J. Burt*, B.K. Bein** and J. Pelz1** \\ Institut für Optik und Quantenelektronik, Friedrich-Schiller-Universität, Max-Wien-Platz I, \\ 07743 Jena, Germany \\ * York-University, Department of Physics and Astronomy, 4700 Keele Street, North York, Canada, \\ $M 3 J I P 3$ \\ ** Ruhr-Universität Bochum, Institut für Experimentalphysik, 44780 Bochum, Germany
}

\begin{abstract}
We present calculated photothermal contrast functions arising from lateral scanning of buried stripe and disk-shaped deviations in thermal conductivity k. From the theoretical findings we derive the measuring conditions in terms of the modulation frequency for which optimal photothermal discrimination of subsurface thermal inhomogeneities can be achieved. The theoretical results have been verified experimentally by measuring model samples, in which localized inhomogeneities were embedded.
\end{abstract}

\section{Introduction}

Photothermal measurement techniques, developed in the last decade, use optically induced thermal waves to detect scattering from thermal inhomogeneities inside opaque solids. Suitable techniques for defect discrimination and localization are now available and can be realized for a wide field of technical applications. These techniques also include photothermal imaging of hidden structures on a microscopic scale.

Photothermal microscopic imaging has to be characterized by the resolving power and the measurement contrast. In this paper we investigate the influence of the measuring conditions on definition and contrast while imaging buried inhomogeneities. Based on the definition of the photothermal Point Spread Function PSF [1] extended thermal inhomogeneities are described and the measurement contrast of the amplitude and phase signal is analyzed. The theoretical contrast dependency on the frequency and the defect depth is compared to experimental results found from suitably prepared model samples.

Once the photothermal PSF is known the object pattern can be reconstructed from the measured images. To this finality, the measuring conditions for optimum photothermal discrimination of subsurface defects have to be known. Results of inverting measured images by means of the photothermal PSF will be reported in a further paper [2].

\section{Theoretical description of photothermal imaging}

In order to quantify the properties and the performance of photothermal imaging we introduced a photothermal Point Spread Function in analogy to classical optics. This complex valued PSF describes the image of a point-like thermal inhomogeneity which is localized at the depth $z_{0}$, while scanning the sample by means of a modulated, point-like heating beam. Obviously, the PSF depends on both the defect depth $z_{0}$ and the modulation frequency $f$.

Under simplified conditions the PSF can be calculated analytically. First of all we assume the photothermal signal is proportional to the average surface temperature. This restriction can be fulfilled if the detection spot diameter is large compared to the thermal diffusion length $\mu$. If the distortions of the 
thermal parameters $\mathrm{k}$ (thermal conductivity) and $\mathrm{ec}$ (heat capacity per unit volume) are small, i.e. the deviations $\Delta k$ and $\Delta(\rho c)$ from the mean values $k_{0}$ and $(\varrho c)_{0}$ are small, we find the PSF for a surface absorbing sample nonuniformity.

$$
G\left(r, z_{0}, \mu\right)=\frac{\pi}{2} \sigma^{2} \frac{1}{\sqrt{r^{2}+z_{0}^{2}}} \exp \left[-\sigma\left(z_{0}+\sqrt{r^{2}+z_{0}^{2}}\right)\right]\left|\frac{A z_{0}}{\sqrt{r^{2}+z_{0}^{2}}}\left(1+\frac{1}{\sigma \sqrt{r^{2}+z_{0}^{2}}}\right)+B\right|
$$

where $\mathrm{A}=\Delta \mathrm{k} / \mathrm{k}_{0}, \mathrm{~B}=\Delta(\rho \mathrm{c}) /(\rho \mathrm{c})_{0}, \sigma=(1+\mathrm{i}) / \mu, \mu=(\mathrm{k} / \rho \mathrm{c} \pi \mathrm{f})^{1 / 2}$ and where $\mathrm{r}$ denotes the lateral distance between the beam and the center of the thermalnonuniformity.

We suppose the layered spatial thermal inhomogeneity to have a distribution $\mathrm{O}\left(\mathrm{r}, \mathrm{z}_{0}\right)=\mathrm{O}(\mathrm{r}) \cdot \delta\left(\mathrm{z}-\mathrm{z}_{0}\right)$. The sample is scanned by a modulated, point-like heating beam. Apart from the spatially uniform signal $S_{0}$ of the homogeneous sample we find a perturbated signal $S$ in the surrounding of the buried thermal nonuniformity, which can be described as $S=S_{0}+\Delta S$. Keeping in mind the meaning of the PSF, the relative signal deviation $\Delta S / S_{0}$ is the convolution of the spatially dependent defect distribution $O\left(r, z_{0}\right)$ and the photothermal PSF $\mathrm{G}\left(\mathrm{r}, \mathrm{z}_{0}, \mu\right)$. When scanning laterally across the buried thermal nonuniformity, one measures a spatial variation of the photothermal signal $S$. Photothermal techniques commonly use vector lock-in amplifiers for measuring amplitude and phase. In terms of this approach we want to describe the detectability of deviations in the thermal properties by means of the amplitude $\left(\mathrm{K}_{\mathrm{A}}\right)$ and phase $\left(\mathrm{K}_{\varphi}\right)$ contrast functions defined in [3]:

$$
\begin{aligned}
& K_{A}=\frac{\left|S_{0}+S_{d e v}\right|-|S|_{0}}{\left|S_{0}\right|} \\
& K_{\varphi}=p h\left(S_{0}+S_{d e v}\right)-p h\left(S_{0}\right)
\end{aligned}
$$

In the case of small deviations in the thermal parameters from the mean values, the contrast functions are directly related to the relative signal deviation. Approximately it follows:

$$
\begin{aligned}
& K_{A} \approx \operatorname{Re}\left[G\left(x, y, z_{0}\right) \otimes O\left(x, y, z_{0}\right)\right] \\
& K_{\varphi} \approx \operatorname{Im}\left[G\left(x, y, z_{0}\right) \otimes O\left(x, y, z_{0}\right)\right]
\end{aligned}
$$

$\mathrm{K}_{\mathrm{A}}$ and $\mathrm{K}_{\varphi}$ are the components of a complex valued function $\mathbf{K}=\mathrm{K}_{\mathrm{A}}+\mathrm{iK}_{\varphi}$ which represents the contrast vector in the complex plane. The projections of this vector $\mathbf{K}$ on the axes correspond to the measurable amplitude and phase contrast. Fig. 1 shows the behaviour of the contrast function $\mathbf{K}$ in the complex plane in dependence on the parameter $\mathrm{Y}=\mathrm{z}_{0} / \mu$ in the case of a point-like distortion, where $\mu$ is the thermal diffusion length. $\mathbf{K}(\mathrm{f})$ describes a closed curve about the origin in the complex plane, passing through all four quadrants when $f$ varies from 0 to infinity. $\mathrm{K}_{\mathrm{A}}$ and $\mathrm{K}_{\varphi}$ show extrema and zero crossings at characteristic $Y$ parameters, corresponding to characteristic modulation frequencies. For a rough estimate the zero crossings of $\mathrm{K}_{\varphi}$ coincide with the extremes of $\mathrm{K}_{\mathrm{A}}$.

By mathematical convolution of the defect distribution and the PSF we are able to calculate photothermal contrast images. As an example Fig. 2 shows phase images of a disk shaped k-defect at different modulation frequencies. From such calculations conclusions about the photothermal imaging features can be drawn:

- There exist contrast extrema at characteristic modulation frequencies. These are different for phase and amplitude contrast and for $\mathrm{k}$ - and $\rho \mathrm{c}$-defects.

- The sign of contrast changes in dependence on $Y$.

- Center contrast of disk shaped defects depends on defect radius $R$. The contrast follows the increase in defect size until it approximates the extremum value at $R=(2 \ldots 4) z_{0}$. Further increasing $R / z_{0}$ does not change the contrast value. 
- Due to the heat diffusion and thermal wave interference the photothermal images are blurred and smeared. The edge definition $\Delta \mathrm{x}$ shows different values for amplitude and the phase contrast depend ing on the measuring conditions, i.e. the images of buried structures are blurred differently in amplitude and phase. In the neighbourhood of the contrast extremes $\Delta \mathrm{x}$ is about $1.8 \cdot \mathrm{z}_{0}$.

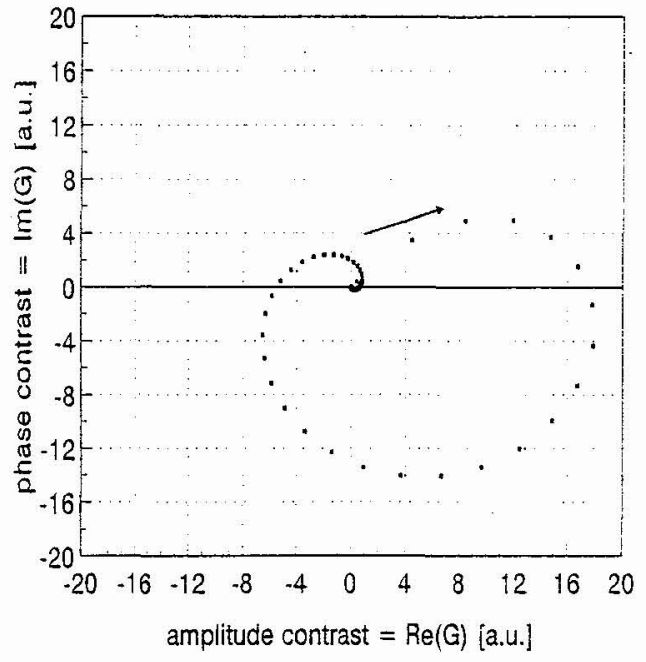

Fig. 1 Generalized contrast function $\mathbf{K}$ for a point defect and pointlike heating; parameter is $\mathrm{Y}$ in steps of 0.05 .
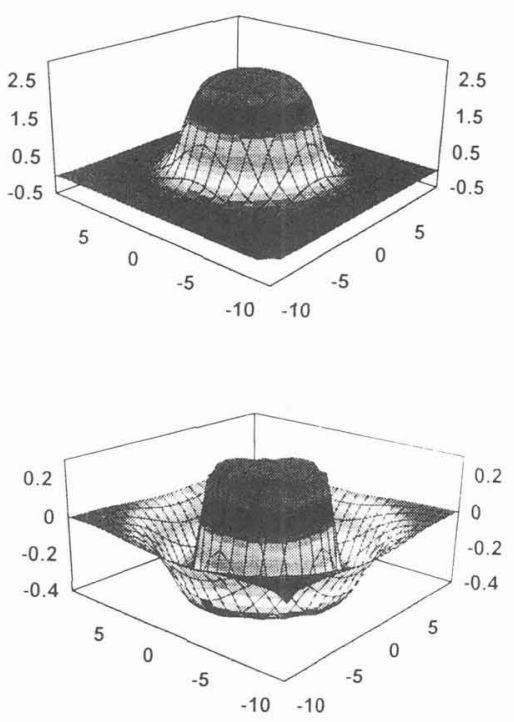

Fig. 2 Calculated phase images of buried disk shaped defects; $\mathrm{R} / \mathrm{z}_{0}=5$, top: $\mathrm{Y}=0.2$, bottom: $\mathrm{Y}=0.5$

\section{Experimental}

We have experimentally verified the dependence of the contrast on the modulation frequency and depth by photothermal measurements on specially prepared model samples. These are made of very thin copper or platinum wires which are embedded in tin solder or lead blocks with polished surfaces. The spatially resolved photothermal measurements were carried out by two different measurement techniques. First we used a Mirage-interferometer, attached to a Laser-Scanning-Microscope [4]. Secondly, we used a photothermal radiometric (PTR) setup equipped with a MCT detector which allows broadband IRdetection in the 2-12 $\mu \mathrm{m}$ wavelength range. In both cases a focussed $\mathrm{Ar}^{+}$laser beam was used for the excitation of the thermal waves. The two measurement techniques provided similar results while scanning the sample, but the signal to noise ratio in the case of mirage interferometry was at least one order of magnitude higher than that of PTR.

Fig. 3 shows typical contrast scans across the sample surface at a distance between sample surface and wire surface of about $50 \mu \mathrm{m}$. These curves are derived from the measured photothermal line scans and show considerable changes of the contrast above the defect at certain modulation frequencies. The amount and the sign of signal deviation strongly depend on the modulation frequency. The signal is superimposed with fluctuations which are only weakly frequency dependent. Because of the reproducible localization of these fluctuations we suppose surface inhomogeneities to be the origin of them.

For comparing the calculated to the experimental contrast curves we consider the extreme values and the zero crossings of amplitude and phase. We label the extreme values of the amplitude by $\mathrm{Extr}_{\mathrm{A}}\left[\mathrm{K}_{\mathrm{Ai}}\right]$ and of the phase by $\operatorname{Extr}\left[\mathrm{K}_{\varphi \mathrm{i}}\right]$, the corresponding abscissa values by $\operatorname{Extr}\left[\mathrm{Y}_{\mathrm{Ai}}\right]$ and by $\operatorname{Extr}\left[\mathrm{Y}_{\varphi \mathrm{i}}\right]$, where $\mathrm{i}=$ $1,2, \ldots$ is the number of the extreme. The zero crossings are labeled by $Y_{0, A i}$ (amplitude) and by $Y_{0, \varphi i}$ (phase). Different depths are denoted for instance by $\operatorname{Extr}\left[\mathrm{K}_{\mathrm{Ai}}\left(\mathrm{z}_{01}\right)\right]$ or by $\mathrm{Y}_{0, \varphi i}\left(\mathrm{z}_{02}\right)$. First we investigate 
the dependence of the signal contrast on the defect depth $\mathrm{z}_{0}$. For a copper wire in tin solder measured at two different depths z01 and z02 we considered experimental abscissa ratios and contrast ratios of certain points. The results are summarized in Tab.1. We want to emphasize the good agreement between the calculated and the measured behavior of the contrast scans demonstrating the value of the PSF concept in photothermal imaging.
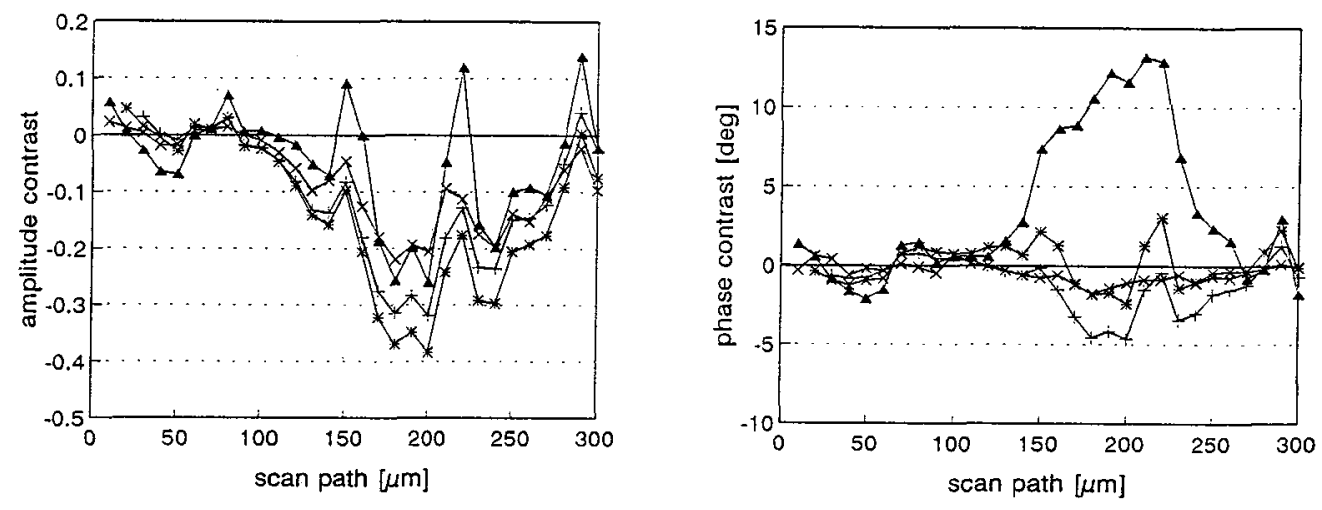

Fig.3 Measured amplitude and phase contrast scans across the "embedded wire" sample at different modulation frequencies: $14 \mathrm{~Hz}(\mathrm{x}), 340 \mathrm{~Hz}(+), 700 \mathrm{~Hz}(*), 6 \mathrm{kHz}(4)$. The copper wire is located at a scan position of about 200 . The distance between the sample surface and the wire surface is approximately $55 \mu \mathrm{m}$.

Table I: Comparison of calculated and measured characteristic abscissa and contrast ratios

\begin{tabular}{||c|c|c|c||}
\hline \hline $\mathrm{R}=40 \mu \mathrm{m}$ & ratio considered & calculated & measured \\
\hline \hline \multirow{3}{*}{$\mathrm{z}_{01}=55 \mu \mathrm{m}$} \\
$\mathrm{R} / \mathrm{z}_{01}=0.73$ & $\operatorname{Extr}\left[\mathrm{Y}_{\varphi 1}\right] / \mathrm{Y}_{0, \varphi 1}$ & 0.45 & 0.51 \\
\cline { 2 - 4 } & $\operatorname{Extr}\left[\mathrm{Y}_{\mathrm{A} 1}\right] / \mathrm{Y}_{0, \varphi 1}$ & 1.05 & 0.97 \\
\cline { 2 - 4 } & $\operatorname{Extr}\left[\mathrm{K}_{\varphi 1}\right] / \operatorname{Extr}\left[\mathrm{K}_{\varphi 2}\right]$ & 0.37 & 0.29 \\
\hline \multirow{3}{*}{$\mathrm{z}_{02}=96 \mu \mathrm{m}$} \\
$\mathrm{R} / \mathrm{z}_{02}=0.41$ & $\operatorname{Extr}\left[\mathrm{Y}_{\varphi 1}\right] / \mathrm{Y}_{0, \varphi 1}$ & 0.43 & 0.52 \\
\cline { 2 - 4 } & $\operatorname{Extr}\left[\mathrm{Y}_{\mathrm{A} 1}\right] / \mathrm{Y}_{0, \varphi 1}$ & 1.13 & 1.08 \\
\cline { 2 - 4 } & $\operatorname{Extr}\left[\mathrm{K}_{\varphi 1}\right] / \operatorname{Extr}\left[\mathrm{K}_{\varphi 2}\right]$ & 0.36 & 0.24 \\
\hline
\end{tabular}

The authors wish to gratefully acknowledge the financial support of the Deutsche Forschungsgemeinschaft (DFG), of the Deutscher Akademischer Austauschdienst (DAAD) and of the Humboldt-Stiftung.

[1] K. Friedrich, K. Haupt, U. Seidel, H.G. Walther, J.Appl.Phys. 72 (1992), 3759 - 3764

[2] U.Seidel, H.G.Walther, J.Burt, "A Proposal for the Reconstruction of Buried Defects from Photothermal Images", 8. Int.Top.Meeting on Photoacoustic and Photothermal Phenomena, Guadeloupe, Jan. 22nd-25th 1994

[3] U.Seidel, K.Haupt, H.G.Walther, J.Burt, B.K.Bein, J.Appl.Phys. 75 (1994), No.8

[4] H.G. Walther, K. Friedrich, K. Haupt, K. Muratikov, A. Glazov, Appl.Phys.Lett. 57 (1990), $1600-1601$ 